\title{
Africa and China Higher Education Cooperation: Establishing Knowledge Sharing Partnership between Students
}

\author{
GONONDO Jean \\ Institute of Educational Research, Zhejiang Normal University, \\ 688 Yingbin Avenue, Jinhua City, Zhejiang Province 321004, China
}

\begin{abstract}
Knowledge sharing should not be confused neither with data sharing nor with information sharing; the knowledge sharing includes data and information sharing, skills and expertise communication, ideas exchange. Since the fourth FOCAC held in Egypt in 2009, many policies have been added to reinforce Africa and China educational cooperation, especially in the area of higher education. And this paper intends to look more closely at this area, particularly with regards to the possibility of establishing and strengthening knowledge sharing, ideas exchange between Africa and China, through African and Chinese students' partnership. Based on the documented trends on Africa and China higher education cooperation, partnership and exchanges, questionnaire surveys, interviews and observations, the author tries to find out whether African students who are studying in China will to collaborate or not with Chinese students during their studies and researches. What are their motivations to cooperate with their Chinese classmates, and how should we beef up and promote knowledge sharing between African and Chinese people through University students' knowledge sharing partnership?
\end{abstract}

Keywords: Africa and China, Higher Education Cooperation; Knowledge Sharing

\section{Introduction}

Exchanges between Africa and China dates back from the ancient time. The establishment of contemporary relations between Africa and China dates back to 1950s when six African countries, Algeria, Egypt, Morocco, Guinea, Sudan and Somalia signed with China for the first time an official bilateral trade agreement. Since the beginning of the $21^{\text {st }}$ Century, the Forum on China-Africa Cooperation abbreviated FOCAC was set up as one of the most important programs and platforms for Africa and China Cooperation. Since its creation, this program gather every three years both African and Chinese Top Leaders either in China or in one African Country. From these perspectives, the cooperation seems to abide by the preached principle of equality between the two parties. Apart from political, economic, cultural issues and programs which are discussed during these fora, education is also one of the main point of focus of FOCAC. This paper analyzes the willingness and the possibilities of establishing knowledge sharing partnership between African and Chinese students. The data used in this research study are derived mainly from questionnaire surveys and interview conducted from January to February 2017 in one of the Chinese Universities in Zhejiang province. Through this study we will be able to first know from the answers of respondents the attitude of African students who are enrolled in Chinese higher education institutions, whether they will or not to share their knowledge with others. We will be able also to understand their impressions about their Chinese classmates concerning knowledge sharing. And finally give some practical suggestions which might promote knowledge sharing between African and Chinese students in the milieu of higher education institutions, susceptible to conduct to the hoped bright partnership between Africa and China.

\section{Theoretical Framework}

\subsection{Insights from the Existing Literature and Background}

Over the past 40 years, through student's mobility, the globalization of higher education has grown considerably and the number of students who study abroad has increased tremendously. This number "has been multiplied by a factor of 4 between 1975 and 2008" (Beine, Noël, \& Ragot, 2014). Foreign students are not only interested in studying in developed countries like USA, England, France etc. but also in developing countries like China, South-Africa, Cameroon etc. In the particular case of Africa and China, even though there are very few studies on Chinese students studying in Africa, but on the other hand, day after day, there is an increasing number of studies on African students in China (Bodomo, 2014). Since China renewed its commitments to cooperate with Africa, "especially in search of raw materials to fuel its growing economy, more and more students from Africa began to arrive in China"(Bodomo, 2014). During their study in China, African students acquire information, knowledge, skills, expertise etc. from their environment, teachers and not the least from their classmates. Reciprocally, African students share and exchange also their ideas, knowledge, skills, experiences etc. with them. Before talking in detail about knowledge sharing between African and Chinese students, we should first know and understand that "Knowledge sharing" should not be confused with "Information sharing", the former expression includes the later one. Knowledge sharing is a human action through which knowledge (data, information, skills, expertise etc.) is exchanged among people or group of peoples. According to (Serban \& Luan, 2002), "Knowledge combines information with individual, group, and organizational experience and judgment, 
and it involves making a leap from understanding relations to understanding patterns that can guide action" as it is represented in the following figure:

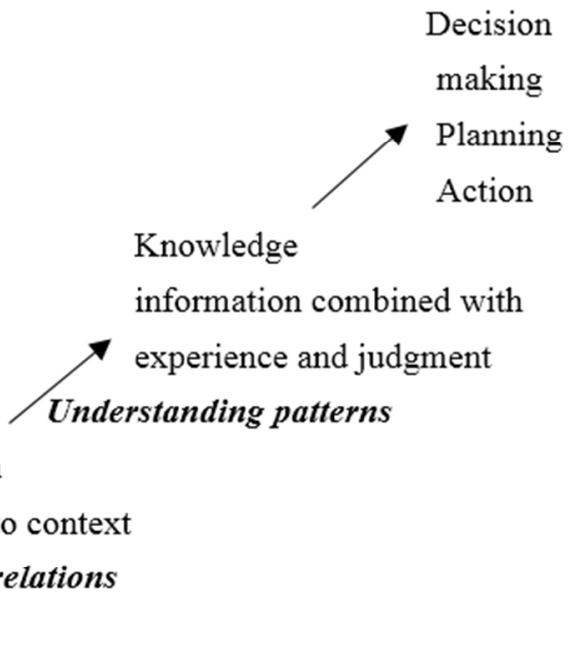

Data

Raw facts and numbers

Knowledge sharing concerns the willingness of individuals to share with others their work-related knowledge, expertise, skills that they have acquired or created (Gee-Woo, W.Zmud, Kim, \& Lee, 2005; Ramayah, Yeap, \& Ignatius, 2014). In the context of higher education, the knowledge sharing refers to the faculty members sharing their work-related knowledge, skills and expertise with others academics. The shared knowledge can be implicit due to its subjectivity, context-specificity, and difficulty to be captured or can be explicit thanks to its objectivity, communication via verbal or visual means, and facility to be codified (Ramayah, Yeap, \& Ignatius, 2014).

In the case of our actual study, during the Forum on China-Africa Cooperation in 2012, both Africa and China have taken as engagement to cooperate in knowledge sharing and ideas exchange partnership. These resolutions can be realized through their engagement by the "transfer of advanced and applicable technologies", the sharing of "experience in the development of science parks", the conduct of "joint research programs"(FOCAC, 2012). Some researchers have also suggested that Africans and Chinese should share with each other their knowledge and exchange their ideas to consolidate their relationship. One of the famous scholars who advocates for the establishment of knowledge sharing between African and Chinese peoples is Professor Liu Hongwu. In December 2015, Professor Liu Hongwu published an article in Chinese language titled: “中非应建 立知识共享与思想交流的伙伴关系” which can be translated to “China and Africa should establish knowledge sharing and idea exchange partnership". In his paper, the author pointed out that nowadays the Development and the Renaissance of China and Africa are not only the economic growth nor the revival of individual Civilization, but it is more of a knowledge reconstruction, ideas improvement (Liu, 2015). He thinks that both China and Africa should gradually expand their cooperation at multi-levels. China's more than 30 years of rapid development experience should inspire Africa to explore new and appropriate road for its development with its own development theory and its own development path. Thus, it is necessary to promote cultural, people-topeople exchanges and knowledge sharing between Africa and China. In the following part of this research study, we are going to analyze the various ways through which African and Chinese students could implement and strengthen the knowledge sharing within the situational contextualization of FOCAC.

\subsection{FOCAC Programs on Higher Education}

"Unlike many traditional donors, such as France and Britain, China does not now, as it once did, cooperate principally with a special sub-set of countries with political, historic, linguistic, geographic or economic ties with the donor country" (King, 2014). Thus, over the past five decades, Africa and China have established and strengthen good friendship and good partnership. Their friendship is deeply rooted in both the African and Chinese people's mind. Through the 《China's Second Africa Policy Paper》 released on Friday, 4 December 2015 in Johannesburg, South Africa during the summit of the Forum on China-Africa Cooperation, the Chinese government believes the fact that "China and Africa have long valued sincerity, friendship and equality, which constitute the underlying rationale for China-Africa relations to grow stronger with time"(Xinhua, 2015).

2.2.1 FOCAC's Brief Historical Background

In October 2000, China organized for the first time FOCAC Ministerial Conference in Beijing. Through Beijing Declaration, a certain number of economic and social development programs have been released. Since that moment, FOCAC has been held every three years alternatively in China and Africa. Some measures have been 
taken to propel higher education cooperation between Africa and China. We have for example to grant more scholarship to African students to study in China; to continue sending Chinese teachers to Africa to help local institutions; to establish channels of communication between African and Chinese universities for mutual civilization study; to set up an African Human Resources Development Fund exclusively to train African Personnel (FOCAC, 2009c).

In December 2003, Ethiopia held the Second FOCAC Ministerial Conference in Addis Ababa. In the context of higher education, the following measures have been taken during this forum for the next three years: train 10.000 African personnel in different fields; teachers exchange; new scholarships; expand African academic discipline and fields of specialization; establish a platform for ideas exchange between African and Chinese institutions of higher learning, Technical and Vocation Education and Training (TVET); exchange of experience and cooperation in science and technology (FOCAC, 2009a).

In November 2006 Beijing held the first FOCAC Summit and third FOCAC Ministerial Conference. Through Beijing Declaration and Action (2007-2009) which was released during this Summit, HU Jintao (China former President) declared eight pragmatic measures and steps to boost the cooperation between Africa and China (FOCAC, 2006a). Concerning the higher education, the following resolutions have been taken: promote more exchanges and closer cooperation between higher education institutions; ensure the effectiveness of the bilateral students exchanges programs; agree on a mutual accreditation of academic degrees; increase the number of Chinese government scholarship to African students (from 2.000 to 4.000 students per year by 2009); provide annual training for educational officials, heads and leading teachers of universities; teach Chinese language in Africa through the establishment of Confucius Institute; encourage the African languages in Chinese universities (FOCAC, 2006b).

In November 2009, Egypt organized the fourth FOCAC Ministerial Conference held in Sharm elSheikh. During this important meeting, the Sharm el-Sheikh Declaration and Action Plan (2010-2012) were released. During this ceremony, WEN Jiabao (former Premier of the State Council of the People's Republic of China) announced eight new measures to strengthen their cooperation (FOCAC, 2009d). In the context of promoting the higher education cooperation between the two entities, both took some engagements, implement cooperation plan between 20 African higher education institutions and 20 Chinese higher education institutions; admit in the next three years 200 high level and middle African administrative personnel to MPA programs in China; raise to 5500 the number of African students to be given scholarships by Chinese government by 2012; intensify teachers training; increase the number of Chinese language learners through the encouragement of developing Confucius Institute. Some resolutions have been also taken in the case of Science and Technology and Technology Transfer in the next three years. For example, carry out 100 joint research and demonstration projects; invite 100 African post doctors to conduct research in China; offer research instruments to all African scientific researchers returning to home country after completion of study in China (FOCAC, 2009b).

In July 2012 the fifth FOCAC Ministerial Conference was held in Beijing. During this forum, there were many new measures encouraging the higher education cooperation between China and Africa. Both Africa and China were engaged in implementing the "African Talents Program"; train 30.000 African professionals in various domains and offer 18.000 government scholarship in the next three years; improve the quality of the training programs; assist Africa for Vocational skills training facilities; train African's technical and professionals personnel; enhancing young African people and African women's job skills; establish Science Technology Cooperation, Knowledge Sharing, transfer of advanced technologies and share experience in the development of science parks (FOCAC, 2012).

The recent FOCAC which is the Second FOCAC Summit and the sixth FOCAC Ministerial Conference was held in Johannesburg, South Africa in December 2015. As the first FOCAC summit held in Africa after the Beijing summit in 2006, through the Johannesburg Declaration and Action Plan (2016-2018) and its " $1+5+10$ " framework, the Johannesburg Summit plays a vital role in the relationship between Africa and China. In this framework " $1+5+10 "$ ", the 1 stands for a new type of strategic, comprehensive and cooperative strategic partnership between Africa and China. As an important pivot for each other, they would become one in supporting each other in the future; 5 represents the five major pillars which are "Political equality and mutual trust, promoting win-win economic cooperation, having mutually enriching cultural exchanges, mutual assistance in security, and solidarity and coordination in international affairs"; and 10 in this framework indicates the 10 cooperation plans to be implemented. This program covers: Infrastructure, industrialization, agricultural modernization, poverty reduction, financial cooperation, public health, green development, peace and security, trade and investment facilitation, and people-to-people exchanges $(\mathrm{He}, 2016)$. Under the " $1+5+10$ " framework, the cooperation between Africa and China is getting into a new development area. Regarding to higher education, the Chinese government decide to boost the number of scholarship by offering 2.000 degree education opportunities in China; offering 30.000 government scholarship; expanding and innovating the training ways for African professionals in the domain of technical management and economic development; training African senior professionals on administration; continue with 20+20 higher institutions cooperation's program; including 
the Chinese language teaching as part of educational systems; establishing more Confucius Institute; assisting African countries to build vocational and technical training facilities or renovate the existing one; training 200.000 local African vocational and technical personnel; providing 40.000 training opportunities to African in China (FOCAC, 2015). After the Johannesburg summit in 2015, the next FOCAC will be held in China in 2018.

2.2.2 Brief Statement

From the above FOCAC historical background, it is clear that African and Chinese people would like to widely spread their cooperation and strengthen their relations. Nowadays, the cooperation between Africa and China has reached a stable level, a mutual confidence and a need of being useful to each other. Thus, it is unavoidably necessary to talk about people-to-people cooperation, knowledge sharing partnership, experience communication and advanced technologies transfer.

In order to improve this study and respond to the research questions, we did a case study to address the theoretical and empirical issues.

\section{Research Methodology}

The number of African Students in China is increasing year after year, especially in these recent years. Studying and understanding their thoughts and behavior concerning the sharing of knowledge, skills expertise and experiences with their Chinese school mates and classmates is very important for a better cooperation and adaptation in the study environment.

Since 2013, the author has been a scholar in the same University where respondents were chosen. Starting from Chinese language learning to higher education studies passing through the program of teaching Chinese to speakers of other languages, the author has gone through many fields of study and he also has some experiences in the above domains.

During this case research study, we will consider the mixture of qualitative and quantitative research methods. Besides the exploration and analyses of documents, his experiences and observations as scholar in this University, the author has also used some research methods such as: the online surveys, the paper-based questionnaires and the interviews. With regards to the questions concerning the profile of the respondents, a large number of detailed questions were posed to African students. After the stage of the questionnaire surveys, the research will be followed by interviews which were administrated to some selected interviewees who also accepted to discuss more about their experiences concerning the above topic.

In the following paragraphs, results obtained in this study will be presented and analyzed.

\subsection{Questionnaire Surveys}

In total, 232 questionnaires were distributed and sent to the participants, but due to some important issues which were not answered, only 215 responses were valid for this study, with a return rate of $92.67 \%$. We are aware that the number of respondents is relatively few for the generalization, but we should note that compared to the number of foreign students in general and African students in particular studying in this University, this number is quite representative for the research population.

We have developed a structured questionnaire to investigate their knowledge sharing, their impression concerning their Chinese classmates about knowledge sharing. To ensure clarity, readability, objectivity and validity of the survey questions as research instrument in this study, we firstly found some people who are not from the actual pool of potential respondents but acted as respondents; and after that, the author, referred to (Walonick, 1995) modified all the items which were not clear for the respondents. Then, the author conducted a pilot study with some African students using some sample; then some minor modifications of the item and wording have been done after their feedback and comments.

The questionnaire contains four sections: (a) demographic basic information and background items; (b) agreement assessment; (c) frequency assessment; (d) interest assessment. After profile part, this questionnaire survey was followed by thirteen items to which respondents were asked to state the extent of their agreement using a 5-point Likert-type scale, ranging from strongly disagree (1) to strongly agree (5); eight other items were presented to the participants to be answered ranging from never (1) to always (5) and 4 last items needed to be ranged from not at all interested (1) to very interested (5).

\subsection{Interview}

The same as quantitative data are very important in a research, it was also very significant to individually meet some African students and listen to their stories and experiences. That is why after questionnaire surveys, this study was followed by some in-depth face-to-face interviews with students. The summary of some interviews will be presented in the following. 


\section{Results and Analysis}

4.1. Demographic Characteristics of Respondents

The statistical tabulation and graphs below show some demographic basic information regarding the gender, the age group, time spent in China, the educational level, and Chinese proficiency level of the respondents. Among the African countries which are maintaining relations with China, the respondents of this questionnaire surveys are from 39 different African countries. These countries are alphabetically listed as below: Algeria, Benin, Botswana, Burundi, Cameroon, Comoros, Cote d'Ivoire, Democratic Republic of Congo, Djibouti, Egypt, Equatorial Guinea, Ethiopia, Gabon, Ghana, Guinea, Guinea-Bissau, Kenya, Lesotho, Madagascar, Malawi, Mali, Mauritania, Mozambique, Namibia, Nigeria, Republic of Congo, Rwanda, Senegal, Sierra Leone, Somalia, South Africa, South Sudan, Sudan, Tanzania, Togo, Tunisia, Uganda, Zambia and Zimbabwe.

Table 1: Demographic Basic Information and Background

Descriptions of the Sample $(N=215)$

\begin{tabular}{|c|c|c|c|}
\hline Variables & Description & Frequency & Percentage (\%) \\
\hline Gender & $\begin{array}{l}\text { Male } \\
\text { Female }\end{array}$ & $\begin{array}{l}145 \\
70\end{array}$ & $\begin{array}{l}67.44 \\
32.56\end{array}$ \\
\hline Age Group & $\begin{array}{l}\text { Less than } 20 \\
20-25 \\
26-30 \\
31-35 \\
36-40 \\
41-45 \\
46-50 \\
\text { More than } 50\end{array}$ & $\begin{array}{l}10 \\
89 \\
70 \\
31 \\
7 \\
5 \\
2 \\
1 \\
\end{array}$ & $\begin{array}{l}4.65 \\
41.4 \\
32.56 \\
14.42 \\
3.26 \\
2.33 \\
0.93 \\
0.47 \\
\end{array}$ \\
\hline Duration in China & $\begin{array}{l}\text { Less than } 6 \text { Months } \\
6-12 \text { Months } \\
\text { 1-2 years } \\
\text { 2-3 Years } \\
\text { More than } 3 \text { Years }\end{array}$ & $\begin{array}{l}76 \\
13 \\
43 \\
38 \\
45\end{array}$ & $\begin{array}{l}35.35 \\
6.05 \\
20 \\
17.67 \\
20.93\end{array}$ \\
\hline Educational Level & $\begin{array}{l}\text { Bachelor } \\
\text { Master } \\
\text { Ph.D. } \\
\text { Chinese Language }\end{array}$ & $\begin{array}{l}77 \\
85 \\
27 \\
26\end{array}$ & $\begin{array}{l}35.81 \\
39.53 \\
12.56 \\
12.09\end{array}$ \\
\hline $\begin{array}{c}\text { Chinese Proficiency Level } \\
\text { (HSK) }\end{array}$ & $\begin{array}{l}\text { HSK } 1 \\
\text { HSK } 2 \\
\text { HSK } 3 \\
\text { HSK } 4 \\
\text { HSK } 5 \\
\text { HSK } 6 \\
\text { Never participated }\end{array}$ & $\begin{array}{l}13 \\
11 \\
13 \\
36 \\
37 \\
20 \\
85\end{array}$ & $\begin{array}{l}6.05 \\
5.12 \\
6.05 \\
16.74 \\
17.21 \\
9.3 \\
39.53 \\
\end{array}$ \\
\hline Source of Finance & $\begin{array}{l}\text { CSC scholarship } \\
\text { Confucius scholarship } \\
\text { Provincial scholarship } \\
\text { University scholarship } \\
\text { Self-sponsoring }\end{array}$ & $\begin{array}{l}85 \\
28 \\
17 \\
17 \\
68\end{array}$ & $\begin{array}{l}39.53 \\
13.02 \\
7.91 \\
7.91 \\
31.63\end{array}$ \\
\hline
\end{tabular}

The above table 1 displays the demographic data of the respondents. The gender repartition of the sample is $67.44 \%$ for male and $32.56 \%$ for female. The age group of most sampled participants is between 20 and 30 with a percentage of $73.96 \%$. The majority of the participants are enrolled in master degree $(39.53 \%)$, then bachelor degree (35.91\%) program. And 58.6\% of those respondents have been in China for more than one year. Concerning the Chinese proficiency level, we should note that HSK is the abbreviation of "Hanyu Shuiping Kaoshi" which stands for the Chinese Proficiency Test. HSK 1 is the lowest level of the Chinese proficiency level, whereas HSK 6 is the highest level. About $60 \%$ of the responded have taken part to the Chinese proficiency test. $39.53 \%$ of our respondents have CSC scholarship while $31.63 \%$ of them are self-sponsoring. Known as CSC, the China Scholarship Council is a non-profit institution which provides "financial assistance to the Chinese citizens wishing to study abroad and to the foreign citizens wishing to study in China"(CSC, n.d.).

\subsection{Responses to Knowledge Sharing Questions}

During this research, one of the most important questions that we asked was if the respondents wish and would like to study and do research with their Chinese classmates, many of them responded that they strongly agree to cooperate with Chinese students in their study and research, only very few respondents answered neutral or 
disagreed as it is shown in the following graph.

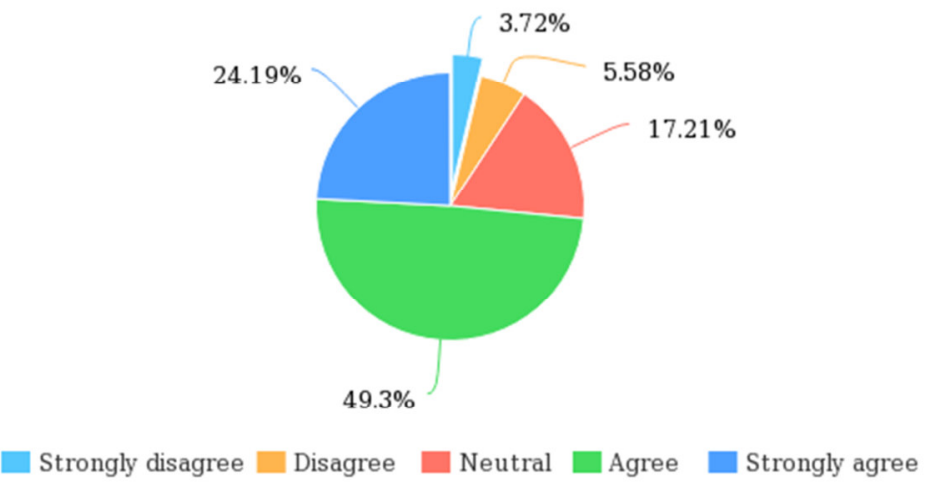

Graph 1. Willingness of Collaborating in Research

Through this answer, we can clearly see and understand the extent to which African students studying in this Chinese University desire and are also ready to collaborate with their Chinese classmates and partner in their study. When further asked the reasons which motivated their choice, they showed various reasons in their answers. $62.79 \%$ of African students who participated in this research think that the main reason they would like to cooperate in study and research with Chinese students is because they work very hard (not represented here). The other reasons which push them to collaborate with their Chinese classmates are: "Chinese students are serious", "I want to get help from them", "Just to help them" etc.

To further probe into the reasons why African students would like to cooperate in their study with their Chinese classmates, we asked other questions concerning their attachment to two other aspects which are the "Chinese language" and "Chinese culture". To the statement concerning Chinese language which was stated as follow: "I like Chinese language", 53.02\% and 32.09\% of those polled responded respectively agree and strongly agree to the statement as we can see in the following graph.

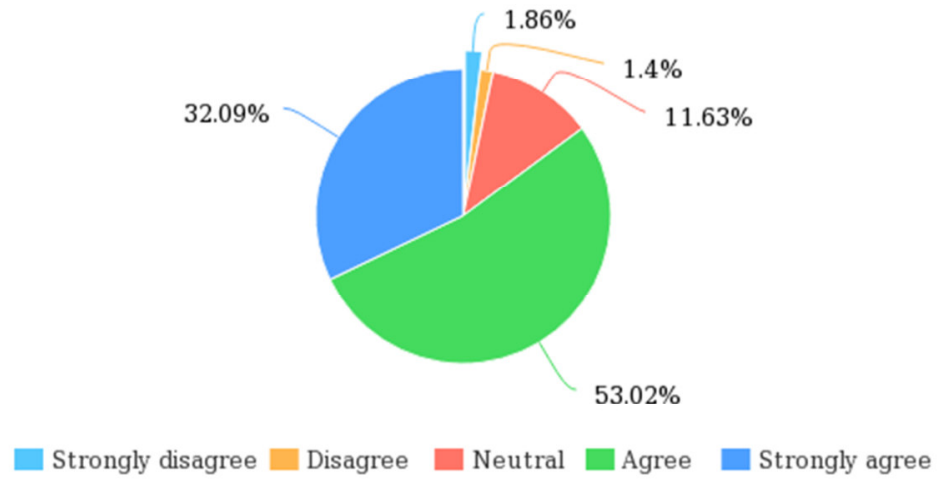

Graph 2. Interest in Chinese language

As it is represented in the above graph, very few number of African students declared negatively to the statement concerning whether they like or do not like Chinese language. To understand exactly whether these African students are interested in Chinese language only after being in China or before coming to china, another question was administrated to them. And we see that many were already interested in Chinese language before coming to China. To know more exactly how deep was their interest in Chinese Language, they were asked to tell us exactly the degree of their interest in Chinese language before coming to China. And finally it was discovered that almost $60 \%$ in total were slightly and very interested in Chinese language before coming to China. 


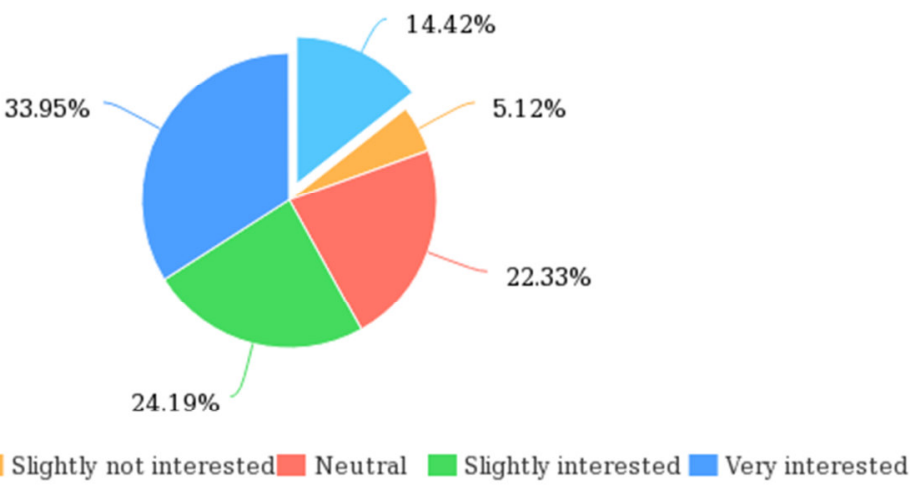

Graph 3. Interested in Chinese language before coming to China

Another crucial set of questions that was also asked focused on the interest of African students concerning the Chinese culture in general. It was discovered that no matter whether before coming to China or after being in China, African students are very interested in Chinese culture. The graphs below represent the degree of their interest in Chinese culture before coming to China and after being in China respectively.

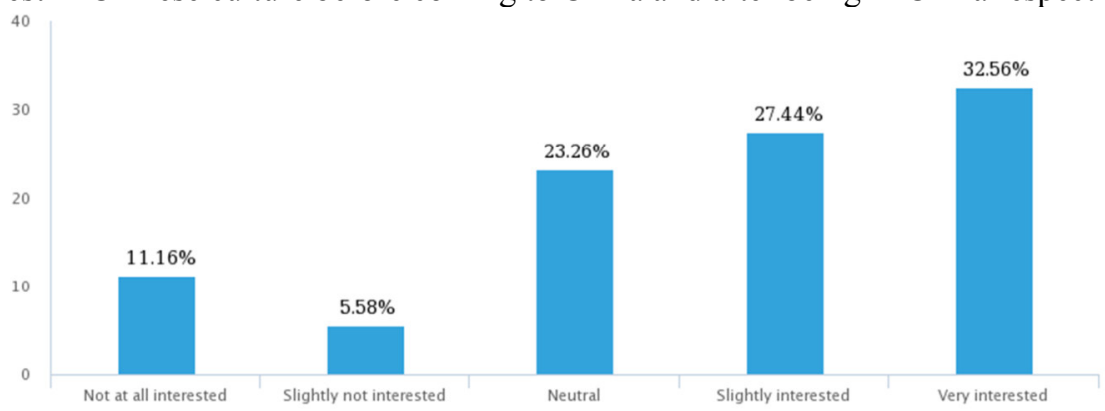

Graph 4. Interest in Chinese culture before coming to China

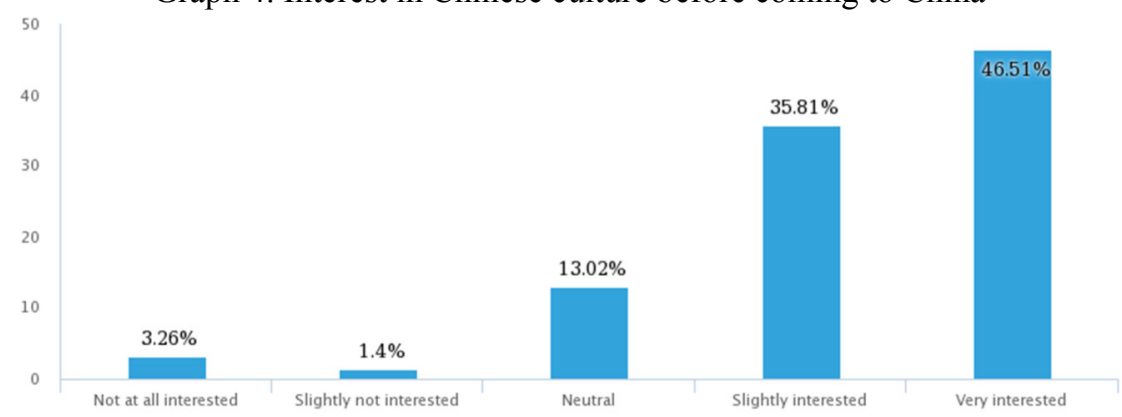

Graph 5. Interest in Chinese culture after being in China.

Through the above issues, one may notice that African students who are studying in China, precisely those studying in the University where respondents were interviewed are mostly interested in Chinese culture. The other aspects which can show the interest of African students in Chinese culture is Chinese food. During this study, only $12.56 \%$ of respondents answered clearly that they don't like Chinese food. $92.09 \%$ of them eat in the university's canteen where almost all the meals and foods are Chinese food. Another aspect of Chinese culture in this study is concerning some habit like eating with chopsticks and drink hot water. We found that before coming to China, $63.26 \%$ of the respondents never ate with chopsticks, $79.07 \%$ never or rarely drink hot water. But after being in China, most of them are used to Chinese culture and behave like Chinese people, $96.29 \%$ of African students use chopsticks to eat while $80.47 \%$ of them are used to hot water.

To know the degree of their willingness as far the knowledge sharing in general is concerned, direct questions were asked whether they are happy or not happy to share their knowledge with others. $46.51 \%$ and $41.4 \%$ answered respectively happy and very happy to share their knowledge with others. The below graph shows more about their answers. 


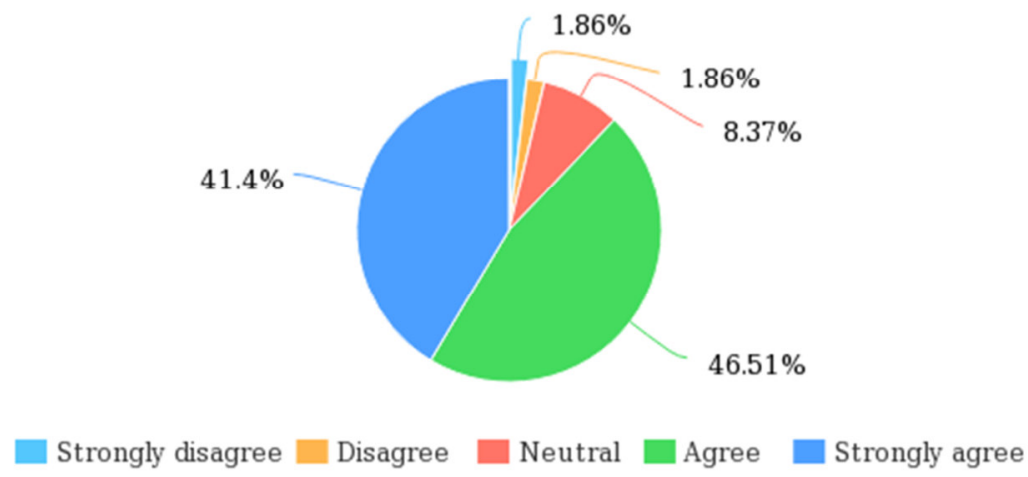

\section{Summary}

Graph 6. Happiness feeling to share knowledge with others.

Although some previous researches show that "most community participants tend to be unwilling to share their knowledge because of a social dilemma associated the sharing behaviors"(C. Liu, Lin, Chang, \& Chao, 2014), therefore in the case of this study the findings show different things. From the above information, we discover that African students who constitute this research population expressed clearly their interest and love for the Chinese language and culture; their willingness to collaborate in study and research with Chinese students; their happiness to share their knowledge with others as it is shown in the above graphs. Even though, some African students' interest in Chinese language and culture increased after being in China, we should note that before coming to China they were already interested in Chinese language and culture. Even though some of these African students are studying programs with English as medium of instruction, during this research, respondents strongly manifested their wish to collaborate in study and research with their Chinese classmates and partners. The reasons why they would like to cooperate in their research and study with their Chinese classmates are multiplied and diversified. Their principal rational motive is that they would like to share their knowledge with others, teaching others their experiences, skills etc. and learning also from others some new skills, experiences etc.

\subsection{In-depth Interviews}

\subsubsection{First in-depth Interview}

Mrs. $M$ is 29 years old, Ph.D. student from Cameroon studying currently "African Education and Social Development". Before coming to China, Mrs. M was a Chinese teacher in her country. After brilliantly obtaining her Master degree in Teaching Chinese to Speakers of Other Languages (MTCSOL) in June 2014 in the same Institution, Mrs. M went back to Cameroon and worked there as a Chinese language teacher in one of the biggest secondary school in the capital of Cameroon, Yaoundé. After two years of Chinese language and culture teaching experience, she got another opportunity to come back to China and now she is enrolled in the same University, faculty of African studies. As a Chinese language teacher, she thinks that it is very important for both African students and Chinese students to promote knowledge sharing. "One should know that while sharing our expertise with others, instead of losing as some of us think, we are reinforcing what we know and we discover many new things", she said. Deciding to come back to China, her aims are: to improve her knowledge of Chinese language, learn some research methodology etc. About the question concerning her impression about Chinese classmates' knowledge sharing, she said: "Chinese students will to help other classmates. For example they have been correcting my language mistakes, explaining to me some cultural terms and behavior several times". About herself she said: "I'm always happy to share what I know and what I can do with others". Mrs. M insists on the fact that the knowledge sharing between African and Chinese students, should be truthful. That is why she said: "African and Chinese students should be sincere in sharing right information and method with each other".

4.3.2. Second in-depth Interview

Mr. T is a 31years old Master student from Mali, he is studying "Foreign Linguistics and Applied Linguistics". Before coming to China last September, he had been teaching English in a secondary school for 5 years in Mali. Coming to China, he expects to improve his English language teaching skills, "I got an opportunity to come to China to improve my English teaching skills and after that I will go back to Mali to teach" he said. Concerning his impression about Chinese students sharing their knowledge with African students, Mr. T said that "Chinese students are reserved". To the question how he is participating to the knowledge sharing with his Chinese classmates and friends, he answered: "In class we have a group for expose, as an experienced teacher I shared with them the way one should present an expose free of fear." To the question what he has learned concretely as 
skills in his cooperation with Chinese students, he answered: "I learned from my Chinese partners to prepare for example a PowerPoint presentation". As suggestions, Mr. T said: "I'm happy to be useful to someone else and glad to know that I can contribute to the happiness of others by sharing my knowledge. Thus, it will be very good to set up some small groups, associations or platforms regrouping African and Chinese students to share their skills".

4.3.3. Third in-depth Interview

$\mathrm{Mr}$. B is a 28 years old young Comorian, and he is currently the only student coming from Comoro in this institution. Since he is enrolled in studying Chinese language program in this great institution since September 2016, he said that he is quite satisfied with his life and study in this University. And he intends to continue his Master's program next year in the same institution with "Comparative Education" as major. Before coming here, Mr. B got a Bachelor degree in "French Modern Letters" and was teaching French language in a secondary school in his country. Coming here, he has many expectations such as "Chinese language learning", "teaching skills", "Chinese culture understanding" etc. His impression about Chinese students is that "They are hardworking", and "Ready to help others". To the question how he can participate to the knowledge sharing with his Chinese classmates and partners, Mr. B said "I'm willing to teach my Chinese friends what I know; for example my national language Shikomoro, French language, Comorian interesting cultural knowledge etc. But I have some obstacles, and the major obstacle is the language barrier. That is why I'm working very hard every day to learn Chinese language with the help of my teachers and classmates."

Summary

The three above face-to-face discussions with African students concern their understanding of knowledge sharing, their aim of coming to China, their impression about Chinese students concerning knowledge sharing with them, the way they share their own knowledge with their Chinese classmates and friends and some pragmatic suggestions to promote knowledge sharing between students especially those coming from Africa and their Chinese partners. To answer to the preoccupation concerning the promotion of an effective knowledge sharing, as Mr. T from Mali said, we should feel happy to share what we know. It is a way we can contribute to the lighting up of others and the way of developing our societies. Mrs. M from Cameroon add to this by saying that, it is a valuable behavior to share one's knowledge with others. We should share with each other not only some basic information, but also skills, experiences, concrete and practical knowledge.

The answers of respondents and interviewees showed that, as "agents of soft power" African students feel happy to share their knowledge with others. Thus, knowledge sharing between African and Chinese students is the bridge for a durable partnership and inseparable friendship between African and Chinese people. It is the main way leading to skills transfer which has been preached for a long time.

\section{Suggestions of Promoting Knowledge Sharing between African and Chinese People, especially in the case of Higher Education Institutions.}

Nowadays, encouraging knowledge sharing is one of the important research topic and also a big challenge. As Abdi thinks, knowledge is a social construction, it represents the contributions of many people (Abdi, 2015). Knowledge sharing is a free will action, it cannot be obliged. Thus, because of its necessity in strengthening a truthful relationship between African and Chinese people, knowledge sharing should be facilitated and encouraged. As a "strong social and cultural organization which is responsible for the transmission and creation of human cultural tradition", Higher education Institution is "different from other social organization identity" (Gonondo, 2016). And "regarded as future decision-makers in society", University students have a high probability of becoming "opinion-shapers"(Chen \& Tsai, 2016). "Academics as faculty members in academic institutions are one of the most important constituencies representing their parent institutions" (Ramayah et al., 2014). Thus, knowledge sharing is becoming inevitably necessary to be practiced between all the members of the institution as a whole and particularly between students. That is why to beef up the true partnership between African and Chinese it is very necessary to:

$\diamond \quad$ Be aware of the value and benefit of possessed knowledge to others

$\diamond$ Have the intention to share our knowledge: A voluntary sharing of an active knowledge is an indispensable factor of a significant, valuable and effective learning at university level (Chong, Teh, \& Tan, 2014).

$\diamond \quad$ Cultivate self-worth through knowledge sharing: "It is believed that the sense of self-worth influences individuals' behaviors" (Gee-Woo et al., 2005). We should consider that, the more we share our knowledge with others, the lesser we become impoverished. As it has been proved by (M.K.Smith et al., 2009), when students discuss question with their neighbors, "the percentage of correct answers typically increases".

$\diamond \quad$ Share knowledge reciprocally: Both African and Chinese should believe that their mutual relationships can be improved and strengthened through a reciprocal sharing of knowledge. One part should not only wait from another party to do it, both parties need to actively participate in ideas exchanges. That is why Professor Kenneth King mentioned that "The emphasis therefore is not on what Africa's developing 
economies can learn from China, but rather on what China and Africa can both learn from each other....the emphasis is on the fact that China and Africa have shared parallel challenges; there is therefore no sense of a one-way learning process"(King, 2013). We should identify classmates, colleagues etc. in need of a specific knowledge and create time to share our knowledge with them. We should increase the contact time, communication, dialogue, and interaction and create a social network between African and Chinese students. Having the willingness of communicating our skills and ability, engage in intellectual debates and discussions, collaborate with others etc. could positively influence the knowledge sharing (Lin \& Lin, 2015; Wangpipatwong, 2009).

$\diamond$ Surmount some differences: In knowledge sharing, one should avoid some differences such as age differences, gender differences, differences in education levels, differences in experience levels, differences in cultural background etc.

$\diamond \quad$ Demonstrate: As partners, African and Chinese should teach to each other not only what the thing is about or what the person has done, but it is more important and needed to know and understand the way things have been successfully done. In January 12, 2017, the African Academy of Social Science, the International Exchange Office, the African Translation Centre in China jointly organized at Beijing International Exhibition Center, translation into English, French, Arabic the first series of documents concerning "China's reform and opening up and Development experience". This first series of ten volumes were meant to introduce to the African Countries, China's national situation and China's development experience (IASZNU, 2017). These series of ten volumes involve a wide range of areas including: "China's poverty reduction strategy and effect", "Yiwu small commodity city evolution history", "China's private economic development", "China's transportation infrastructure", "China's intangible cultural heritage protection", "China's rural and urban construction", "China's tourism economy and culture", "Development of vocational and technical education in China", "Development of Chinese basic education" and "Chinese Movies". This kind of good initiative taken by the Chinese institutions and scholars should be encouraged. But as some interviewees remarked, the "knowledge sharing" should not stop at the level of information sharing, but it is more important to progress to skills and expertise sharing. The true "knowledge sharing" consist in communicating, divvying up willingly the way of doing something with someone. It will be seen great if besides informing others in what domain we succeed and excelled, we can show and teach them how we made it.

\section{Conclusion}

The objective of this study was to understand the willingness and find out some possibilities of knowledge sharing between African and Chinese people especially among students. The cooperation between Africa and China does not only concern raw materials, but it is also and even more important about knowledge sharing and ideas exchange. Thus, it is inevitably essential to promote dialogue, communication between African and Chinese people. At this level of relationship between the two entities, their relationship should be recognized by a natural true ideas communication, knowledge sharing. Both should create a sincere mutual respect of cultural diversity. If a frank and real knowledge sharing does not exist between the African and Chinese students who are going to be the future partners and decision-makers of the Africa-China cooperation, it is without doubt that realizing the better dreamed and hoped relationship between both Africa and China would not be easy.

\section{Acknowledgments}

Thanks are due to Miss. DJIRARO MANGUE Celestine Laure and Mr. GUIAKE Mathias for their help in distributing and collecting questionnaire. I'm also thankful to Mr. ADEKUNLE OSIDIPE, Mr. EWNETU TAMENE and Miss AYUK Solange for their thoughtful critiques and comments.

\section{References}

Abdi, A. A. (2015). Globalisation and Africa: Critical Historical and Deconstructive/Reconstructive Epistemic Reflections. In E. Shizha \& L. Diallo (Eds.), Africa in the Age of Globalisation: Perceptions, Misperceptions and Realities (p. 21). Canada: ASHGATE.

Beine, M., Noël, R., \& Ragot, L. (2014). The determinants of international mobility of students. Economics of Education Review, 41(2014), 40-54. https://doi.org/10.1016/j.econedurev.2014.03.003

Bodomo, A. (2014). Africans in China: The Experiences from Education and Training Africans in China: The Experiences from Education and Training. Beijing.

Chen, C.-L., \& Tsai, C.-H. (2016). Marine environmental awareness among university students in Taiwan: a potential signal for sustainability of the oceans. Environmental Education Research, 22(7), 958-977. https://doi.org/10.1080/13504622.2015.1054266

Chong, C. W., Teh, P.-L., \& Tan, B. C. (2014). Knowledge sharing among Malaysian universities' students: Do personality traits, class room and technological factors matter? Educational Studies, 40(1), 1-25. 
Retrieved from http://web.b.ebscohost.com/ehost/detail/detail?vid=6\&sid=6ddcbf44-9449-424a-8e8327ce04d2221b\%40sessionmgr120\&bdata=Jmxhbmc9emgtY24mc210ZT1laG9zdC1 saXZl\#AN=2013$44971-002 \& \mathrm{db}=\mathrm{psyh}$

CSC. (n.d.). China Scholarship Council. Retrieved March 1, 2017, from http://en.csc.edu.cn/About/c309df7fb3fa40b3a179a7ad93f11988.shtml

FOCAC. (2006a). Address by Hu Jintao President of the People's Republic of China at the Opening Ceremony of the Beijing Summit of the Forum on China-Africa Cooperation. Retrieved February 8, 2017, from http://www.focac.org/eng/ltda/dscbzjhy/SP32009/t606840.htm

FOCAC. (2006b). Forum On China-Africa Cooperationbeijing Action Plan (2007-2009). Retrieved March 4, 2017, from http://www.focac.org/eng/ltda/dscbzjhy/DOC32009/t280369.htm

FOCAC. (2009a). Forum on China-Africa Cooperation-Addis Ababa Action Plan(full text). Retrieved March 4, 2017, from http://www.focac.org/eng/ltda/dejbzjhy/DOC22009/t606801.htm

FOCAC. (2009b). Forum On China-Africa Cooperation Sharm El Sheikh Action Plan (2010-2012). Retrieved March 4, 2017, from http://www.focac.org/eng/ltda/dsjbzjhy/hywj/t626387.htm

FOCAC. (2009c). Programme for China-Africa Cooperation in Economic and Social Development. Retrieved March 4, 2017, from http://www.focac.org/eng/ltda/dyjbzjhy/DOC12009/t606797.htm

FOCAC. (2009d). Speech by H.E. Wen Jiabao at the Opening Ceremony of the 4th Ministerial Conference of the Forum on China-Africa Cooperation. Retrieved February 8, 2017, from http://www.focac.org/eng/ltda/dsjbzjhy/zyjh/t627391.htm

FOCAC. (2012). The Fifth Ministerial Conference Of The Forum On China-Africa Cooperation Beijing Action Plan (2013-2015). Retrieved March 4, 2017, from http://www.focac.org/eng/ltda/dwjbzjjhys/hywj/t954620.htm

FOCAC. (2015). The Forum on China-Africa Cooperation Johannesburg Action Plan(2016-2018). Retrieved March 4, 2017, from http://www.focac.org/eng/ltda/dwjbzjjhys 1/hywj/t1327961.htm

Gee-Woo, B., W.Zmud, R., Kim, Y., \& Lee, J. (2005). Behavioral Intention Formation in Knowledge Sharing: Examining the Roles of Extrinsic Motivators, Social-Psychological Forces, and Organizational Climate. MIS Quaeterly, 29(1), 87-111.

Gonondo, J. (2016). University campus culture connotation , characteristics and functions. International Journal of Acadmic Research and Development, 1(10), 36-40. Retrieved from http://www.academicsjournal.com/archives/2016/vol1/issue10/1-10-22

He, W. (2016). Sino-African Ties in the Fast Lane. BEIJING REVIEW, 25. Retrieved from www.chinafrica.cn

IASZNU. (2017). 面向非洲的《中国改革开放与发展实践》丛书在京首发（图） [Introducing “China's reform and opening up and Development experience"series to Africa starting in Beijing (FIG.)]. Retrieved February 11, 2017, from http://www.zjnu.edu.cn/news/common/article_show.aspx?article_id=20620

King, K. (2013). China's Aid \& Soft Power in Africa: The Case of Education \&Training. Woodbridge: James Currey.

King, K. (2014). China's Higher Education Engagement with Africa: A Different Partnership and Cooperation Model? Education, Learning, Training: Critical Issues for Development, International Development Policy series No.5 (pp. 151-173). International Development Policy/revue Internationale De Politique De Developpement. https://doi.org/10.4000/poldev.1788

Lin, Q., \& Lin, L. (2015). Factors Influencing Knowledge-Sharing Behaviors and Learning Effect: a Multilevel Investigation. Social Behavior and Personality, 43(10), 1683-1698. https://doi.org/10.2224/sbp.2015.43.10.1683

Liu, C., Lin, C., Chang, C., \& Chao, P. (2014). Knowledge sharing among university students facilitated with a creative commons licensing mechanism: a case study in a programming course. Educational Technology \& Society, 17(3), 154-167. Retrieved from http://web.b.ebscohost.com/ehost/pdfviewer/pdfviewer?vid=4\&sid=6ddcbf44-9449-424a-8e83$27 \mathrm{ce} 04 \mathrm{~d} 2221 \mathrm{~b} \% 40$ sessionmgr 120

Liu, H. (2015). 中非应建立知识共享与思想交流的伙伴关系[China and Africa should establish a partnership of knowledge sharing and exchange of ideas]. 当代世界[Contemporary World], 18-19.

M.K.Smith, W.B.Wood, W.K.Adams, C.Wieman, J.K.Knight, N.Guild, \& T.T.Su. (2009). Why Peer Discussion Improves Student Performance on In-Class Concept Questions. Retrieved from www.sciencemag.org

Ramayah, T., Yeap, J. a L., \& Ignatius, J. (2014). Assessing Knowledge Sharing Among Academics: A Validation of the Knowledge Sharing Behavior Scale (KSBS). Evaluation Review, 38(2), 160-187. https://doi.org/Doi 10.1177/0193841x14539685

Serban, A. M., \& Luan, J. (2002). Overview of Knowledge Management. New Directions for Institutional Research, 113(113), 5-16. https://doi.org/10.1002/ir.34 
Walonick, D. S. (1995). Survival Statistics - an applied statistics book for graduate students (Steps to Follow When Designing a Survey). Retrieved March 4, 2017, from http://www.statpac.org/researchlibrary/survey-design-process.htm

Wangpipatwong, S. (2009). Factors influencing knowledge sharing among university students. In Proceedings of the 17th International Conference on Computers in Education (pp. 800-807). Hong Kong. Retrieved from http://www.apsce.net/icce/ICCE2009/pdf/C6/proceedings800-807.pdf

Xinhua. (2015). CHINA DAILY. Retrieved February 4, 2017, from http://www.chinadaily.com.cn/world/XiattendsParisclimateconference/201512/05/content_22632874.htm 